\title{
A incongruência do argumento da antítese moral em Hobbes
}

\author{
The incongruence of the moral antithesis argument in Hobbes
}

do $10.21680 / 1983-2109.2021 v 28$ n57ID23503

\author{
Delmo Mattos Silva \\ Universidade Federal do Maranhão (UFMA) \\ 0000-0002-9074-2192 \\ delmomattos@hotmail.com
}

Resumo: $\mathrm{O}$ objetivo desse artigo consiste em fornecer uma crítica às pretensões de Strauss em determinar um fundamento moral à filosofia civil de Hobbes. Trata-se, portanto, de discutir as determinações do comportamento dos homens derivado de uma tendência natural a eles imposta. Desse modo, expõe-se a viabilidade do vínculo entre a filosofia natural e a filosofia civil para determinar o comprometimento de Hobbes aos termos do mecanicismo da sua época. Sendo assim, inviabiliza-se o argumento de Strauss segundo o qual o princípio da autopreservação baseia-se em uma antítese moral ocasionada entre a vaidade e o fundamentalmente justo medo da morte violenta.

Palavras-chaves: Hobbes, vaidade, filosofia civil, mecanicismo, medo.

Abstract: The aim of this article is to provide a critique of Strauss' claims to determine a moral foundation for Hobbes' civil philosophy. It is therefore a question of discussing the determinations of man's behavior derived from a natural tendency imposed upon him. In this way, the viability of the link between natural philosophy and civil philosophy is exposed in order to determine Hobbes' commitment to the terms of the mechanism of his time. Strauss' argument that the principle of self-preservation is based on a moral antithesis between vanity and the fundamentally just fear of violent death is thus made impossible.

Keywords: Hobbes, vanity, civil philosophy, mechanism, fear.

\section{INTRODUÇÃO}

Um dos intérpretes mais reconhecidos da teoria política de Hobbes, Strauss (2016), propõe interpretar os aspectos fundantes do seu sistema filosófico e político demonstrando a inconsistência da exclusividade do argumento que atesta a relação de dependência estabelecida entre os princípios da sua filosofia da natureza, caracterizada como filosofia primeira, e da sua filosofia política e moral. Essa relação de dependência entre os objetos da física e os objetos da moral fornece, dessa forma, um reforço de sistematização do argumento da necessidade de 
vinculação das partes que compõem o sistema filosófico de Hobbes, no tocante aos elementos da filosofia natural e aos aspectos teóricos do mecanicismo.

Os intérpretes da vinculação entre os elementos da filosofia natural e os da filosofia política e moral de Hobbes constroem uma linha argumentativa na qual o princípio da autopreservação resulta em uma aplicação particular da teoria cinética aos seres vivos. O axioma fundamental em que se persegue a interpretação secularista de Hobbes é aquele segundo o qual todo corpo busca preservar o seu movimento. Desse modo, a manutenção do movimento constitutivo do corpo transforma-se na própria condição fundamental da sua identidade, isto é, a preservação da vida.

Strauss (2016) opõe-se a relação que a interpretação secularista procede aos termos do projeto filosófico e político de Hobbes, ao inviabilizar a proposta de explicar o comportamento dos homens derivado de uma tendência natural a eles imposta. Contrariando as determinações interpretativas majoritárias de Hobbes, a perspectiva de Strauss alicerça os fundamentos da sua filosofia civil, baseada em uma nova atitude moral humanista. Essa atitude moral na qual se funda a filosofia civil não necessita percorrer, por sua vez, uma via de acesso para a obtenção dos princípios da moral pelo método analítico.

Seguindo o pressuposto de desvinculação entre a reflexão filosófica e política de Hobbes e os princípios da filosofia natural, Strauss (2016) atribui à constituição de uma base moral para a filosofia civil uma antítese entre o medo da morte violenta e a superação da vaidade. $O$ argumento do referido autor enfatiza que a filosofia civil hobbesiana se baseia em um novo fundamento de moralidade. A relação, exposta pelo autor citado, entre as paixões da vaidade e do medo da morte desencadeia o argumento de que a necessidade de obtenção de poder não resulta de uma aplicação do fato da natureza aos homens, mas da expressão da vaidade humana.

Utilizando-se desse viés, Strauss (2016) assevera que os princípios da filosofia natural não contribuem para a compreensão correta dos pressupostos do sistema hobbesiano, assim como interferem na compreensão da necessidade de atribuir o fundamento moral como princípio norteador da filosofia civil. Além disso, essa falta de distinção qualitativa entre o princípio natural e o princípio moral, no âmbito da reflexão filosófica e política de Hobbes, produz um equívoco no modo de extrair o fundamento e a exigência do Commonwealth.

Ao demonstrar essa via de interpretação, Strauss (2016) vincula o fundamento da moral da filosofia civil de Hobbes utilizando-se dos aspectos morais ine- 
rentes à natureza humana, especialmente expressos nas determinações do medo da morte violenta. Fazendo uso do argumento do medo da morte violenta, o autor descaracteriza o postulado mecanicista do sistema hobbesiano, e enquadrando o princípio da autopreservação a um critério de justiça pelo qual ressalta uma antítese moral ocasionada entre a vaidade e o fundamentalmente justo medo da morte violenta. Trata-se, pois, do que Strauss denomina "base da filosofia política de Hobbes" (2016, p. 68).

Não obstante, o argumento que identifica a aproximação teórica entre o sistema de Hobbes e o conceito de movimento na física de Galileu, isto é, o princípio de inércia, demonstra que Hobbes vincula os conceitos da física aos preceitos da sua filosofia civil. Tal argumento justifica-se também pela conformidade intelectual de Hobbes ao advento das novas concepções da "nova ciência" pelo qual o axioma fundamental da sua reflexão filosófica e política confere o princípio de inércia o postulado fundamental da natureza humana: "todo corpo busca manter um equilíbrio constante de suas diferentes partes mantendo a sua identidade".

Considerando o aspecto mecanicista do pensamento hobbesiano, a manutenção do movimento constitutivo de um corpo transforma-se na condição fundamental da conservação de sua própria identidade, isto é, da sua vida. Diante disso, fica, portanto, evidente, que a necessidade de obtenção de poder resulta de uma aplicação do fato da natureza aos homens, de modo que todo corpo busca perseverar no seu movimento.

Para Hobbes, a manutenção do movimento constitutivo de um corpo transforma-se na condição fundamental da conservação de sua própria identidade, isto é, da sua vida. Dessa forma, o poder de autoconservação constitui-se por uma aptidão natural de obtenção e distribuição permanente de energia que os corpos finitos dispõem. Disso segue que a relação do incremento deste poder é proporcional ao incremento da "capacidade de distinção e identidade de uma coisa particular". Com isso, justifica-se o argumento da plausibilidade de vincular os preceitos da filosofia civil aos preceitos da filosofia natural.

Diante ao exposto, o objetivo fundamental do presente artigo é descaracterizar o argumento de Strauss, de que o princípio determinante para a preservação da vida é o medo justo da morte violenta. Esse argumento inviabiliza as determinações científicas no interior do sistema de Hobbes para enfatizar o pressuposto da vaidade, ou seja, um elemento com um aspecto moral, em detrimento pressuposto de desejo de poder e mais poder sob uma circunstância puramente mecânica do movimento. Assim, contrariando o argumento de Strauss, a filosofia natural, presente no discurso político de Hobbes é determinante para explicar o ser hu- 
mano como um ser natural, e como tal está condicionado às mesmas leis e aos princípios que regem os fenômenos naturais porque compartilha certos aspectos e propriedades gerais com os objetos da classe dos corpos em geral: o princípio universal dos corpos, isto é, o movimento.

Para demonstrar esse pressuposto teórico, em um primeiro momento, problematiza-se a antítese na qual a filosofia civil de Hobbes se baseia, isto é, aquela entre a vaidade como apetite natural e o medo da morte violenta como paixão. Através dessa antítese busca-se determinar o medo como um único critério pelo qual todo homem pode orientar a vida dos homens. Diante disso, examina-se a relação entre as ações justas e injustas pela qual são determinadas a atitude de um homem justo e a atitude de um homem injusto.

Em um segundo momento, debate-se o argumento da dependência entre a filosofia civil e a filosofia primeira. Nesses termos, discute-se a problemática da fundamentação da filosofia política de Hobbes quanto à sua dependência aos princípios das ciências naturais ou filosofia natural. Esta relação atesta o vínculo estabelecido por Hobbes entre a sua teoria política e os argumentos que caracterizam a sua "teoria física", uma vez que esta refere-se à questão da "identidade e unidade" de um corpo finito ao qual o filósofo deduz o "axioma da identidade". Da mesma forma, o "axioma da identidade" que vincula os preceitos da filosofia civil aos preceitos da filosofia primeira de Hobbes demonstrando efetivamente o seu comprometimento aos termos do mecanicismo da sua época.

\section{A ANTÍTESE MORAL CONTRA O FUNDAMENTO CIENTÍFICO DA FILOSOFIA CIVIL}

Strauss (2016) afirma que a antítese na qual a filosofia civil de Hobbes se baseia é aquela entre a vaidade como apetite natural e o medo da morte violenta como paixão. Esse pressuposto ressalta uma desvinculação, assinalada por Hobbes, entre a acepção do Commonwealth enquanto corpo político e o homem enquanto corpo natural, analogamente aos corpos artificiais e corpos políticos. $\mathrm{Na}$ perspectiva de Strauss (2016), essa relação não é suficiente para deduzir o papel preponderante na constituição do sistema filosófico e político de Hobbes ${ }^{1}$.

Se pressupor a relação de dedução entre os elementos da filosofia natural e a filosofia civil não é algo plausível, resta a Strauss deduzir a necessidade de ob-

\footnotetext{
1 "A tentativa de deduzir a lei natural ou moral do direito natural de autopreservação ou, em outras palavras, do poder inescapável do medo da morte violenta, levou a modificações muito significativas no conteúdo da lei moral. A modificação acarretou, em primeiro lugar, uma simplificação considerável. O pensamento ao longo dos séculos XVI e XVII tendeu em geral a uma simplificação da doutrina moral” (STRAUSS, 2016, p. 266).
} 
tenção do poder e mais poder da vaidade humana. A vaidade enquanto paixão fornece os argumentos fundamentais para demonstrar a antítese que justifica o fundamento da moral da filosofia civil. Segundo Strauss (2016), os pressupostos da vaidade denotam a caracterização da natureza humana, em Hobbes, motivada por um egoísmo. Há, nesse sentido, um caráter belicoso na natureza humana em decorrência da vaidade que conduz cada homem a se sobrepor ao outro (KIDDER, 1982).

Através desse modo de reconduzir as determinações da vaidade, Strauss (2016) pode, utilizando-se dos argumentos do De Cive, evidenciar a relação entre o apetite natural e a razão natural. Desse modo, pode explicar que a causa e a origem do apetite natural relacionam-se ao desejo de "satisfazer-se apreciando a sua própria superioridade", que, por sua vez, representa o que é próprio da vaidade. Em relação à razão natural, a sua causa e origem é o medo da morte violenta por outro homem.

Na visão de Strauss (2016), os dois postulados em questão evidenciam uma nítida oposição, isto é, se a vaidade conduz ao enfrentamento entre os homens devido à "força fundamentalmente injusta que torna os homens cegos" (GREENLEAF, 1980, p. 59). Como consequência, instaura a guerra de todos contra todos. Em contrapartida, o temor da morte violenta em uma situação na qual o desejo de cada um pode triunfar sobre outro conduz a uma condição de efetivar a paz.

As determinações morais presentes nessa oposição são visíveis. Segundo Toto (2016), a vaidade é uma orientação para uma conduta mortal entre os homens. Constitui-se em princípios imorais, dos quais expõe uma condição de aniquilamento da vida. Por sua vez, o medo da morte violenta constitui um princípio moral capaz de conduzir os homens a uma situação de proteção da vida.

Diante do que foi explicitado, há de se supor uma tensão entre a paixão da vaidade e o medo da morte violenta a partir de um critério moral, ao passo que se atribui à vaidade um valor fundamentalmente injusto e ao medo da morte violenta um valor fundamentalmente justo. A oposição entre valor justo e valor injusto e entre a vaidade e o medo da morte introduz uma reflexão sobre os critérios para se determinar a intenção de uma ação. Conforme assinala Strauss (2016), Hobbes reconhece que não é a legalidade da ação que torna o homem justo, mas o propósito da ação. Nesse caso, se a intenção da ação conduzir a um propósito justo, não há incursão em determinar que foi motivada por orgulho ou vaidade².

\footnotetext{
2 “É notável que Hobbes prefira a expressão negativa "evitar a morte” à expressão positiva "preservar a vida" (STRAUSS, 2016, p. 54).
} 
Toda intenção que promove um propósito da ação direcionado à vaidade e ao orgulho são atitudes injustas, segundo Strauss (2016). No entanto, uma ação motivadora pela autopreservação possui um propósito justo, porque a sua intenção provém de algo que é absolutamente necessário. Se realmente for assim, o medo da morte deve ser considerado o fundamento de todas as intenções justas.

Na perspectiva de Strauss:

O homem justo é aquele que cumpre a lei porque é lei, e não por medo do castigo ou em nome da reputação. Embora declare que são demasiado severos consigo mesmos e com os outros os que defendem que os primeiros movimentos da menta (ainda que contidos pelo temor de Deus) sejam pecados, ele no entanto "confessa" que "é mais seguro errar nessa direção do que outra (2016, p. 62).

Quando atribuída às ações, concebe Hobbes, a concepção de justo significa agir conforme o direito; de outra forma, agir de forma injusta é agir contra o direito. Partindo dessa premissa, o filósofo enfatiza que, por um lado, quem age conforme o direito se diz que é inocente e, por outro lado, agir em desconformidade com o direito atribui-se o termo culpado. Nessa relação, segundo Stauffer (2010), um homem cujas ações são justas não se transforma em um homem justo, na medida em que se considera justo o homem capaz de agir com justiça ou de acordo com o direito. Contudo, Strauss (2016) ressalta que uma atitude justa é aquela que não é conforme a obediência a lei, mas a autoconfiança.

Esse modo de refletir a relação de como são processadas as ações justas e injustas faz com que Strauss (2016) distinga a atitude de um homem justo da atitude de um homem injusto. Para o autor, a atitude justa diz respeito àquela que conforma o medo da morte a uma convicção interna. O que consistirá no homem justo é a "vontade de praticar ações justas" conforme sejam dirigidas ações para evitar a morte, enquanto o que constitui o homem injusto é a vontade determinada de obedecer às leis por medo de uma punição (KIDDER, 1982).

Afirmar que uma ação é praticada por medo ou por bravura é o mesmo que afirmar que essa ação é conforme a vontade de quem a praticou, pois o processo que finda a deliberação decorre da determinação de uma vontade que prevaleceu sobre as demais. Por conseguinte, as ações resultantes dessa determinação são ainda condicionadas pela vontade (will), que é o "último apetite ou aversão imediatamente anterior à ação ou à omissão desta" (HOBBES, 1968, p. 127).

No The elements of law, Hobbes assevera que: "o apetite, o medo, a esperança e as demais paixões não são chamadas voluntárias, pois elas não procedem da vontade, mas são a vontade; e a vontade não é voluntária” (2002b, p. 84). Nesses 
termos, pode-se inferir que a vontade quando não é voluntária é ato, isto é, um ato de querer ou desejar que dela derive uma ação voluntária.

Hobbes insiste na definição de que "um homem livre (free-man) é aquele que, naquelas coisas que graças à sua força e engenho é capaz de fazer, não é impedido de fazer o que tem vontade de fazer (to do what he has a will to)" (1968, p. 262). Disso decorre que onde existe uma conformidade entre ação e vontade há necessariamente liberdade. Assim, não existe contradição entre uma ação praticada em decorrência da "ausência de impedimentos internos ao movimento" e aquela decorrente da "ausência de impedimentos externos ao movimento", na medida em que um "ato livre" depende dessas duas condições para se realizar.

Ora, se um homem se vê em uma situação na qual é preciso escolher entre executar uma ação em decorrência do medo de certas consequências ou praticar uma ação que vise fundamentalmente a proteger a sua vida, ele age livremente. Nesses dois casos, tem-se, portanto, duas ações em que a vontade é determinada por um desejo anterior, seja do medo das consequências de não a praticar, seja da perda da proteção da vida e, consequentemente, a morte.

Segundo Strauss:

A redução da intenção justa ao orgulho é um desvio do pensamento-chave de Hobbes. Não o orgulho, e ainda menos a obediência, mas o medo da morte violenta é, de acordo com ele, origem da intenção justa. O que o homem faz levado pelo medo da morte, na consciência da sua fraqueza nas mãos de outros homens, quando ele confessa honestamente a si mesmo e aos outros a sua fraqueza e o seu medo da morte, despreocupado com a sua honra, e apenas isso é fundamentalmente justo (2016, p. 64).

A justiça, quando atribuída às ações cuja finalidade é evitar a morte, tornase imprescindível na forma de avaliar possíveis danos pelos quais os riscos à autopreservação em breve tornam-se real. Segundo Leivas, "a gradação do medo é natural ao homem e funciona como critério individual de avaliação de males futuros" (2011, p. 348). Considerando essa perspectiva, consoante Hobbes, o medo de outros homens, assim como qualquer outro medo particular, exige de cada homem experiência que, em associação com a razão prudencial calculadora, motiva a busca por segurança.

O medo da morte violenta propicia um cálculo futuro que motiva uma razão prudencial $^{3}$. Assim, Strauss (2016) determina o medo como um único critério pelo qual todo homem pode orientar a sua vida. Não há, portanto, um critério natural que possa orientar a autopreservação. Considera-se, ainda, que a morte não é ape-

\footnotetext{
${ }^{3}$ Em nota ao De Cive, Hobbes esclarece o que entende propriamente por medo: “Compreendo, porém, na palavra medo, uma certa antevisão de um mal futuro, por isso não penso que fugir seja o único efeito do medo; a quem sente medo ocorre desconfiar, suspeitar, acautelar-se e até mesmo agir de modo a não mais temer" (2002a, p. 359).
} 
nas uma negação do bem primário, mas de todos os outros bens, incluindo o bem maior: a felicidade.

Enquanto um mal maior, a morte permite o que Strauss (2016) determina de prosperar contínuo pelo qual os homens satisfazem qualquer apetite. Trata-se, pois, de um objetivo que determina um sentido para as ações humanas, que são direcionadas para evitar a própria morte. Nesse sentido, a morte é um mal primário, mas também é o mal supremo que conduz os homens à obtenção da razão.

A morte consiste na negação do bem primário e supremo, observa Strauss (2016), que é a preservação da vida. A relação entre o desejo e os "objetos de desejo" tem matizes importantes na configuração das ações humanas para Hobbes. A necessidade de discernir objetos "bons" de objetos considerados "maus" para a preservação do movimento ou da vida encontra a sua expressão mais fundamental na explicação do filósofo de que os homens desejam, acima de tudo, evitar a morte e que, por esse motivo, todo homem considerará a sua autopreservação como o "bem maior, e a morte o mal maior". Dessa maneira, a aversão à morte é, para Hobbes, outra forma de expressar o desejo de preservação da vida.

Não obstante, nas condições em que predomina uma perpétua disposição para o combate, a conservação da vida torna-se inviável, tendo em vista que a competição pelo poder como estratégia de sobrevivência resulta em uma situação de "insegurança generalizada", através do medo constante, por parte de cada homem, da morte violenta imposta pelos demais. Tal paradoxo, segundo Kidder (1982), é engendrado pela situação de insegurança e belicosidade inerente ao estado de natureza, no qual, considerando a igualdade dos homens e a busca incessante pelo poder e mais poder, se favorece uma diminuição das condições necessárias para a preservação da vida.

Nesses termos, Hobbes expressa que o "homem torna-se lobo para o próprio homem", ou seja, cada homem é, para os demais, um inimigo em potencial, pois, em decorrência da ausência de tal poder, os homens existem em um desprazer da companhia dos outros, que está relacionado com a sua falta de aptidão natural para manter uma convivência pacífica. Não obstante, é através da satisfação dos desejos individuais e na conservação da vida que os homens são capazes de descobrir quais são os meios adequados para alcançar os fins desejados e, por conseguinte, de agir não apenas obedecendo às suas paixões naturais, mas de seguir o seu próprio interesse.

Dessa forma, em conformidade com a reta razão, isto é, como uma "proposição disposicional de propagação da autoconservação da vida", devido à sua fórmula mais extensa, aquela que se refere ao "jus in omnia", o direito natural vai de 
encontro aos princípios da legitimação do "estado de guerra", o qual será empreendido pelos homens como absolutamente contraditório à própria conservação da vida (KIDDER, 1982). Nesse sentido, Skinner, afirma: "embora a paz seja nossa necessidade básica, a guerra é nosso destino natural” (1999, p. 42).

Disso resulta uma nítida contradição, pois, se todos os homens são autorizados pelo direito natural a preservarem a sua vida e a utilizar todos os meios necessários à consecução deste fim, é racional que desenvolvam "mecanismos antecipatórios" para projetar situações futuras a fim de conservar a sua vida através da aquisição de poderes e "bens futuros". Assim, da mesma forma, cada homem é levado a supor que há uma "relação de simetria entre a quantidade de poder e a quantidade de bens", de modo que, ao acumular a sua "quantidade de bens", aumentaria a sua quantidade de poder. Portanto, na perspectiva de Toto (2016), a característica acumulativa de poder e bens assegura não apenas um acréscimo de poder de um homem em relação a outro, mas, sobretudo, sugere regras que indicam aos homens os meios mais adequados para atingir o seu objetivo maior, a saber, a preservação da vida.

O medo da morte é, conforme ressalta Strauss (2016), um ato justo; justificase, por conseguinte, o fato moral do sistema de Hobbes no direito, e não propriamente o dever. Se for assim, fica evidente o aspecto de fundamento do direito natural pelo estabelecimento do medo da morte violenta como o real princípio da moralidade. A moralidade presente no discurso hobbesiano, entre a vaidade e o medo, ainda segundo o autor citado, acentua a possibilidade de uma conciliação entre moralidade e prudência, o que serve de princípio regulador das ações humanas. Seguindo esse argumento de Strauss (2016), é através da relação entre vida e morte que as ações humanas são julgadas como boas ou más, ou como justas ou injustas.

Diante disso, Strauss (2016) deduz que a origem da intenção justa é o medo da morte violenta. Para o autor, Hobbes identifica a consciência do medo da morte como um elemento determinante da razão natural, ou seja, é através do medo da morte violenta que determina as razões pelas quais os homens devem calcular os benefícios de um acordo. Assim, Strauss (2016) acentua que é mediante o medo da morte violenta que os homens adquirem os motivos pelos quais torna-se vantajoso evitar, ao máximo, a própria morte. ${ }^{4}$

Se Hobbes atribui determinada culpa ao homem por essa redução do apetite natural à vaidade, logo o medo da morte, que é oposto da vaidade, deve também

\footnotetext{
4 "Hobbes identifica a consciência com o medo da morte; apenas por meio do conhecimento do risco mortal, conhecimento que é ao mesmo tempo um recuo em relação à morte, pode o homem ser radicalmente liberado da vaidade natural, da absorção natural no mundo da própria imaginação" (STRAUSS, 2016, p. 65).
} 
ter um significado moral, e o estabelecimento do Estado deve possuir um significado moral. Nesse caso, segundo Toto (2016), o medo da morte violenta seria a paixão principal que conduz os homens ao uso da razão, e a vaidade, por sua vez, seria o fundamento do apetite natural.

Strauss (2016) assegura que o apetite humano, tal como Hobbes expõe, não seria como o apetite natural, uma vez que, nesse último, o desejo resume-se aos "objetos do presente". Disso decorre que o apetite humano vislumbra "os objetos futuros", tornando-o o mais predatório de todos os animais. Consoante Pacchi (1987), o apetite animal distingue-se do humano, pois o primeiro é originado das impressões externas, reduzindo o seu desejo aos objetos finitos, ao passo que os homens direcionam a sua conduta aos objetos de forma infinita. Conforme depõe Strauss (2016), essa pressuposição pode ser confirmada pelo desejo humano pelo poder e mais poder 5 .

Na perspectiva de Pacchi (1987), esse desejo de poder satisfaz um princípio determinante de um juízo moral decorrente da superioridade que cada homem exige um do outro. Esse comportamento, atribuído por Strauss (2016) a um comportamento imoral, condiciona os homens a uma competitividade pela valorização do poder de cada um pelo outro. Não se trata, então, de acúmulo mecânico ou fisiológico que determina o acúmulo de poder sobre os outros, mas nas qualidades pessoais, isto é, na honra que eles adquirem na comparação uns com os outros. Portanto, ainda na visão de Strauss (2016), Hobbes reduz o apetite natural do homem à vaidade, pois o apetite do homem consiste na vaidade na medida em que, na sua constituição, procura superar os seus semelhantes a fim de possuir sua superioridade reconhecida por todos os outros.

Conforme explana Strauss,

O temor pela proporia vida, que adveio ao homem na sua luta por triunfo, modera, elimina mesmo a vontade de triunfar, tornando-o pronto a se submeter, a deixar o triunfo ao inimigo a fim de salvar a sua própria vida. Mas então o inimigo, que obteve o que queria, ou seja, garantir o reconhecimento da sua superioridade, da sua honra, não pode, em nome da mesma honra, matá-lo; pois "nada senão o medo é capaz de justificar tomar a vida de outrem. E como o medo dificilmente pode ser manifesto a não ser por alguma ação desonrosa, que trai a consciência da própria fraqueza [...] (2016, pp. 60-61).

\footnotetext{
5 “É o que ocorreria, por exemplo, com o postulado do apetite natural. Explicados a partir de uma concepção mecânica da natureza, a infinitude do desejo e a busca do poder não seriam suscetíveis de julgamento moral; contudo, afirma o comentador [Strauss], essa não poderia ser a verdadeira intenção de Hobbes, pois a busca do poder 'é sempre boa e permissível ou má e inadmissível'. Ainda que Hobbes tente sustentar uma ilusão de amoralidade, 'ele não é mais capaz do que qualquer outro de nos fazer esquecer que o homem não é um animal inocente" (FRATESCHI, 2008, p. 55).
} 
Conforme assinala Pacchi (1987), segue que a vanglória é uma espécie de lente de aumento que o homem coloca sobre si mesmo e suas supostas qualidades. Por essa razão, Hobbes afirma: "a vanglória consiste na invenção ou suposição de capacidades que sabemos não possuir" (1968, p. 45). A partir dessa paixão, o homem tende a se colocar em relação aos outros com superioridade ou mesmo menosprezar a capacidade alheia e supervalorizar a própria (BATES, 1974). Essa descabida glorificação de si mesmo tem, geralmente, efeito negativo nas relações que o homem estabelece com os seus iguais. Segundo Blits (1989), a vanglória diz a um homem que o outro não é igual a ele, mas sim sempre inferior. Tal perspectiva possui implicações na forma como os homens se relacionam.

\section{O ERRO DE STRAUSS E A CIENTIFICIDADE DA POLÍTICA: A DEPENDÊNCIA ENTRE A FILOSOFIA CIVIL E A FILOSOFIA PRIMEIRA}

No Prefácio ao De Cive, redigido em 1647, ou seja, após a Epístola dedicatória, Hobbes propõe uma classificação diferenciada do seu projeto de sistematização do conhecimento. Essa classificação leva em consideração os vários tipos de movimentos que compõem os diversos ramos do conhecimento e inclui, por sua vez, o movimento como objeto de conhecimento da filosofia primeira e alguns elementos da física.

A passagem em questão é a seguinte:

Estava estudando filosofia por puro interesse intelectual, e havia reunido o que são seus primeiros elementos em todas as espécies e, depois de concentrá-los em três seções de acordo com os graus, pensei escrevê-lo de modo que se apresentasse da seguinte forma: na primeira trataria do corpo, e das suas propriedades gerais; na segunda, do homem e de suas faculdades e afetos especiais; na terceira, do governo civil e dos deveres dos súditos. De modo que a primeira parte conteria a filosofia primeira, e certos elementos da física; nela consideraríamos as razões de tempo, lugar, causa, poder, relação, proporção, quantidade, figura e movimento. Na segunda discutiríamos a imaginação, a memória, o intelecto, o raciocínio, o apetite, a vontade, o bem e o mal, o que é honesto ou desonesto, e coisas parecidas. O que a última parte aborda é que vou expor (HOBBES, 2002a, p. 17-18).

Nessa passagem, Hobbes omite a geometria, reduzindo o seu objeto de contemplação à filosofia primeira. Tal constatação, em certo sentido, pressupõe que a filosofia primeira se baseia tanto nos objetos de estudo da geometria como nos objetos da física. Desse modo, pode-se pressupor que ambas as áreas compartilham o mesmo grau de importância na ordem de exposição da ciência. Não obstante, contrariando as determinações do que o Prefácio ao De Civeparece denotar, o filósofo, no De Corpore (1655), afirma que, antes de tratar da física, é preciso considerar as propriedades da geometria. Diante dessa afirmação, Hobbes rea- 
firma a posição real da geometria na composição do seu sistema filosófico, à medida que a conduz a uma posição privilegiada em relação às demais ciências.

A primazia da geometria frente às demais ciências na ordem posicional do sistema filosófico explica-se pelo fato de Hobbes concebê-la como a "ciência geral do movimento" (BALDIN, 2017). Ao contrário do que a Epístola dedicatória do De Cive parece denotar, a geometria constitui-se como anterior à física, e, para adquirir o conhecimento dos objetos que compõem esta, faz-se necessário recorrer às noções elementares daquela. As noções elementares da geometria explicam, pois, os movimentos das partes constitutivas dos corpos e seus efeitos, ou seja, os objetos da física. Levando em consideração esse fato, conclui-se que, após a física, chega-se à filosofia moral.

A posição da filosofia moral após a física justifica-se pelo argumento da relação de dependência que ambas mantêm entre si. Hobbes explica essa relação argumentando que os movimentos da mente (tais como o apetite, a aversão, o amor, a benevolência, a esperança, o medo, o ódio, a emulação, a inveja etc.) são objetos de estudo da moral, que, por sua vez, possuem as suas causas na sensação e na imaginação, objetos de estudo da física. Essa relação de dependência lógica, na qual o conhecimento de um depende necessariamente do conhecimento do outro, revela o argumento da ligação entre a filosofia primeira e a filosofia moral.

A respeito disso, Hobbes comenta da seguinte forma:

A filosofia civil e a filosofia moral não aderem tanto uma à outra que não possam ser separadas. Pois as causas dos movimentos da mente são conhecidas não apenas pelo raciocínio, mas também pela experiência de todo homem que se preocupa em observar esses movimentos em si mesmos (1966, p. 122).

Apesar de a passagem referida assinalar a relação de dependência entre filosofia civil e filosofia moral, a possibilidade de se interpretar a filosofia civil como independente da filosofia primeira pode ser pensada e exigida para uma compreensão da função da moral no âmbito da reflexão filosófica hobbesiana. A proposta de Hobbes, no que concerne à sistematização da sua reflexão filosófica, consiste em desenvolver as suas especulações sobre os elementos da filosofia, iniciando com a geometria e a física, que compõem a filosofia primeira, depois a filosofia moral e, em outro registro, a filosofia civil. No Prefácio ao De Cive, Hobbes explicitará as razões pelas quais precisou deixar os estudos da geometria e da física, que seriam a primeira parte do seu sistema filosófico, para tratar da política e da ética mais cedo do que esperava.

Esse relato de Hobbes anuncia e justifica claramente a execução invertida do seu programa científico diante das conturbações políticas pelas quais passava a Inglaterra, ou seja, a ameaça efetiva de guerra impediu-o de dar continuidade à elaboração do seu sistema científico tal como pretendia, o que o fez, em caráter de 
urgência, modificar o objeto de estudo e a ordem programática que pretendia compor o seu sistema filosófico.

Por isso, em vez de iniciar a composição do seu sistema com as investigações do corpo e de suas propriedades gerais, que corresponderiam à filosofia primeira, Hobbes entendeu ser imprescindível começar o seu sistema pelo fim, escrevendo e publicando primeiro o De Cive, que constituiria a última parte do sistema dedicada ao estudo dos corpos políticos. Entretanto, ao inverter a ordem programática do seu sistema, publicando em primeiro lugar o que era para ser a última parte, ou seja, o De Cive, Hobbes desvincula-a das demais partes que compõem o seu sistema filosófico.

Tal desvinculação corrobora a possibilidade de conceber uma relação de independência entre a filosofia civil e a filosofia primeira, à medida que o conhecimento dos princípios da moral pode ser obtido analiticamente pelo procedimento resolutivo. No entanto, pelo método analítico, o conhecimento dos princípios da filosofia civil é completamente autônomo em relação aos princípios da filosofia primeira. Todavia, esse expediente não é exclusivo para se conhecer os princípios do Commonwealth, visto que o método sintético também pode ser solicitado quando se privilegia o conhecimento que cada parte da exposição das ciências mantém com os resultados da que a antecede.

Como ficou estabelecido, a filosofia civil pressupõe o conhecimento das "disposições, afetos e costumes dos homens", ou seja, o conhecimento dos movimentos da mente, que são, portanto, objetos da filosofia moral. Sendo assim, a instituição do Commonwealth, isto é, a sua causa genética, pode ser obtida sinteticamente pelo expediente compositivo. Nesse caso, a filosofia civil tem que ser concebida como dependente dos princípios da filosofia primeira.

Ora, a utilização do expediente de prova do método sintético, por Hobbes, pode ser explicada da seguinte forma: ao utilizar o procedimento do cálculo e os princípios que constituem a sua filosofia primeira, Hobbes poderia fornecer, no Leviathan, as reflexões que vinha procedendo e que não foram efetivadas devido à ameaça de guerra no seu país. De fato, em muitos momentos da obra mencionada, especialmente na sua primeira parte, encontram-se vários princípios contidos naquela que seria a primeira parte do seu sistema. Esse fato pode ser confirmado mediante a afirmação do próprio Hobbes, no Prefácio ao De Cive, de que a última parte do seu sistema estaria fundamentada em princípios próprios, isto é, em fa- 
tos da experiência, não se reportando à dedução a partir dos princípios da filosofia primeira $^{6}$.

Na perspectiva de Adams (2017), Hobbes reconhece que o conteúdo da filosofia moral próximo ao método analítico seria o suficiente para superar o problema da persuasão da filosofia civil. Assim, Hobbes certificou-se de que a aceitação de suas teses políticas não dependeria exclusivamente da retidão demonstrativa do método sintético, mas das ferramentas do convencimento e da persuasão. A opção do filósofo de privilegiar o método analítico pode ser explicada pelo seguinte argumento: a possibilidade de atingir um espectro mais amplo de leitores e, ao mesmo tempo, convencê-los da pertinência de suas teses.

Esse prisma de leitura contribui para a difusão de suas ideias, uma vez que pode ser compreendida pelo público em geral, leigo em matéria de filosofia, pois estabelece uma via de prova e convencimento mais simples e direta. Como tal, permite ao leitor um expediente de prova mais singular, isto é, a análise direta dos fenômenos mentais conhecidos por todos os homens, que os poupa da tarefa de dedução lógica exclusiva da razão. Nesse caso, compreende-se a simultaneidade entre a via analítica e a via sintética, em virtude da relação de dependência da filosofia civil com a filosofia moral. Portanto, fica patente que o conhecimento da filosofia civil depende logicamente do conhecimento da filosofia moral, seja pelo método sintético ou analítico. Strauss (2016) explica que essa dependência nada mais é do que a demonstração da unidade da atitude moral inserida no interior do projeto filosófico e político de Hobbes.

Strauss (2016) argumenta que essa atitude moral está presente desde a fase embrionária do projeto de sistematização da reflexão filosófica e política de Hobbes, influenciando, inclusive, o modo como as ciências naturais são inseridas nesse projeto ${ }^{7}$. Não obstante, o referido comentador despreza a possibilidade da autopreservação em Hobbes ser um atributo incontestável da aplicação de um princípio natural à natureza humana. E, segundo Baldin, "assim condicionado pelo princípio de inércia resulta daquele princípio expresso sob as condições de um corpo finito" (2017, p. 33). Desse modo, Hobbes orienta os seus argumentos no sentido de demonstrar que as faculdades humanas são resultantes de um princípio geral, isto é, em um princípio universal.

\footnotetext{
${ }^{6}$ Esse é o principal argumento dos defensores da posição de que a filosofia política hobbesiana é independente da filosofia primeira.

${ }^{7}$ Segundo Strauss: "Pois, se o apetite natural humano é a vaidade, isso significa que o homem se empenha por natureza em exceder todos os seus semelhantes e em ter sua superioridade reconhecida por todos os outros, de modo que tenha prazer em sua própria consideração; e que deseja naturalmente que o mundo inteiro o tema e o obedeça” (2016, p. 33).
} 
Strauss (2016) examina o problema da fundamentação da filosofia política de Hobbes quanto à sua dependência e independência aos princípios das ciências naturais ou da filosofia natural, deslocando a problemática metodológica para a apreensão do objeto de investigação da filosofia política ${ }^{8}$.

Essa reorientação investigativa promovida por Strauss (2016) evidencia, por sua vez, que os objetos da filosofia política de Hobbes e os da filosofia natural, embora distintos, compartilham uma fundamentação, isto é, os pressupostos da moral. De fato, como assinala Brandt (1928), a possibilidade de alternância entre os métodos analítico e sintético demonstra o objeto da moral com um ponto comum ao acesso aos pressupostos da filosofia civil. No entanto, essa evidência não é explicitada, pois, segundo Strauss, Hobbes preocupa-se em obstruir essa confluência entre os objetos da moral e os da filosofia civil, destacando os elementos da ciência moderna como aqueles sob os quais a sua sistematização política pode efetivamente fundar-se.

Strauss (2016) assevera que o fundamento do sistema hobbesiano baseado em pressupostos científicos não se justifica, uma vez que, por sua própria natureza, não fornece subsídios para determinar, por exemplo, se a concepção de conservação do movimento transporta-se de uma questão estritamente biológica para ser entendida como uma forma social da segurança dos indivíduos. Todavia, se efetivarmos um paralelo entre a concepção de movimento da física moderna e a "teoria cinética" hobbesiana demonstra-se que, tanto o "axioma do movimento" da física moderna, como os princípios da "teoria cinética" de Hobbes se fundamentam no postulado concernente à conservação do movimento.

Se esses "corpos vivos", isto é, os seres humanos possuem as mesmas propriedades e princípios dos corpos em geral, não seria contraditório poder aplicarlhes a um princípio eminente da teoria física, ou seja, o princípio de inércia. A aplicação do princípio de inércia aos "seres humanos" obedece a uma via dedutiva que apresenta os seguintes enunciados e conclusão: (1) todo corpo que pertence ao conjunto dos corpos que se encontram em movimento tende a perseverar nesse estado; (2) existem corpos finitos que pertencem "a uma subclasse de corpos animados" que se encontram em um estado cinético específico determinado pelos desejos e aversões que experimentam em relação às suas sensações, ou seja, encontram-se em um estado de movimento; (3) todo ser vivo se "esforça para perseverar em seu estado de movimento" a menos que algum impedimento externo o impeça disso.

\footnotetext{
8 “A filosofia política naturalística necessariamente leva à eliminação da noção de justiça enquanto tal. Graças à base moral da sua filosofia política e apenas graças a ela, Hobbes manteve a possibilidade de reconhecimento da justiça enquanto tal e da distinção entre direito e poder" (STRAUSS, 2016, p. 66).
} 
Logo, a capacidade que todo ser vivo possui de conservar seu estado de movimento constitui em um ato de preservação de si próprio, ou melhor, constituise em um ato de autoconservação. Isto implica a autopreservação de uma unidade como idêntica a si mesma enquanto for possível a manutenção do seu movimento. Esta condição é o que possibilita e justifica o aspecto fundamental da natureza humana, a inevitabilidade da morte e a possibilidade constante de sua "antecipação pela violência, pela doença, entre outras mazelas" (BARBOSA FILHO, 1989, p. $63)^{9}$. O axioma fundamental do movimento expõe a condição na qual os seres vivos são determinados no âmbito do sistema político de Hobbes. Segundo Barbosa Filho (1989), essa condição revela o estatuto natural dos seres vivos como seres finitos na natureza. Diante desse estatuto, ou melhor, sob esta condição da existência, são determinadas as condições de geração e instituição do Commonwealth, na medida em que a sua constituição contém no seu aspecto fundamental a natureza humana enquanto um elemento natural sem, no entanto, qualquer pressuposto moral.

Ao conceber a natureza humana como aquela que está condicionado às leis e aos princípios que regem os fenômenos naturais, Hobbes infere que eles compartilham de certos aspectos e propriedades gerais com os objetos da classe dos corpos em geral. Na visão de Barbosa Filho (1989), esse será o ponto de partida que se impõe a fundamentação da filosofia civil na medida em que Hobbes pretende estabelecer a política como uma ciência rigorosa advinda da natureza.

Essa consideração relaciona-se perfeitamente com o projeto de uma "ciência unificada" e, portanto, com a utilização da via sintética, atesta a filosofia moral e a filosofia civil como aquela ciência rigorosa e dedutiva capaz de explicar corretamente a gênese do Commonwealth utilizando-se como referência as faculdades e os predicados da natureza humana.

Nesse sentido, justifica-se essa afirmação, posicionando-se por meio do argumento de que Hobbes não manteve fiel a tese de que a morte seria o maior dos males sob a ótica puramente moral, mas em uma convicção baseada na filosofia natural na qual se pressupõe o movimento como condição de obtenção de poder.

Com o favorecimento da interpretação baseado nos elementos científicos, o pressuposto da vaidade, ou seja, um elemento com um aspecto moral, foi substituído pelo pressuposto de desejo de poder e mais poder sob uma circunstância puramente mecânica do movimento. Esse posicionamento de Hobbes, consoante

\footnotetext{
${ }^{9}$ De acordo com Barbosa Filho: “(...) quanto maior for o poder de autoconservação da coisa particular face às causas exteriores, mais realidade terá a coisa e mais claramente ela poderá ser distinguida como possuindo natureza e uma individualidade definida" (1989, p. 63).
} 
Strauss (2016), constitui-se propriamente a ruína do projeto filosófico hobbesiano, pois o "naturalismo consistente" que o filósofo articula nas suas principais obras não pode fornecer o fundamento legítimo para a sua filosofia civilio ${ }^{10}$.

No entanto, a visão do referido autor, desconsidera a admissão da base mecanicista como aquela capaz de fornecer os indicativos fundamentais da verdadeira fundamentação da filosofia civil de Hobbes, na medida em que a filosofia natural conjugada aos elementos da filosofia civil demonstra as categorias da natureza humana submetidas aos mesmos efeitos dos elementos naturais. Dessa forma, o poder de autopreservação se constitui por esta aptidão natural de obtenção e "distribuição de energia" que os seres finitos dispõem. Na perspectiva de Barbosa Filho (1989), a relação do incremento do poder de autopreservação é proporcional ao incremento da capacidade de distribuição da identidade de uma coisa particular, ou seja, quanto mais poder alguma coisa possui mais distinta ela se torna.

Esse argumento evidencia o axioma da filosofia natural que orienta a filosofia civil de Hobbes, ou seja, aquela segundo o qual os seres humanos se esforçam por incrementar o seu poder de autopreservação o que, de certa forma, consiste em manter a sua vida e a sua identidade como um ser finito e desejante na natureza. Sendo assim, o movimento que os seres humanos realizam no sentido de preservar a sua vida é caracterizado mediante uma especificação do tipo de movimento particular como um movimento natural de autopreservação denominado de conatus ou movimento vital.

Nessa acepção, o postulado do apetite natural defendido por Strauss, não subsiste a dedução da natureza humana da mecânica da natureza para explicar a busca pelo poder. Com isso, a evidência do postulado conforme o qual as determinações da filosofia civil hobbesiana baseiam-se em uma concepção de direito natural sensível aos princípios propriamente científicos é plausível.

Essa constatação depõe a favor de que ao vincular a natureza humana aos elementos subjacentes à filosofia natural, não prevalece uma diferença significativa contida entre direito natural e apetite natural. Diferença o qual Strauss (2016), força uma justificação equivocada do que consiste na base da filosofia política de Hobbes. Trata-se, portanto, de um equívoco incongruente com as determinações do filósofo que ocasiona uma insuficiência com os traços mais fundamentais ca-

\footnotetext{
${ }^{10}$ Dessa forma, Strauss afirma: “Assim, não a antítese naturalista entre apetite animal moralmente indiferente (ou da moralmente indiferente luta humana pelo poder) e a moralmente indiferente luta pela autopreservação, mas a antítese moral e humanista entre a vaidade fundamentalmente injusta e o fundamentalmente justo medo da morte violente é a base da filosofia política de Hobbes” (2016, pp. 66-67).
} 
pazes de explicar a conduta humana atrelado a uma força mecânica externa ao movimento natural de desejo.

\section{REFERÊNCIAS}

ADAMS, M. P. Natural philosophy, geometry, and deduction in the Hobbes-Boyle debate. Hobbes Studies, v. 30, n. 1, p. 83-107, 2017.

BALDIN, G. Hobbes e Galileo: metodo, materia e scienza del moto. Firenze: Leo S. Olschki Editore, 2017.

BATES, S. The motivation to be just. Ethics, v. 85, n. 1, p. 1-17, 1974.

BERNS, W. Judicial review and the rights and laws of nature. The Supreme Court Review, V. 1982, p. 49-83, 1982.

BLITS, J. H. Hobbesian fear. Political Theory, v. 17, n. 3, p. 417-431, 1989.

BRANDT, F. Thomas Hobbes' mechanical conception of nature. London: Hachette, 1928. BARBOSA FILHO, B. Condições de autoridade e autorização em Hobbes. Revista de filosofia política, Porto Alegre, n. 4, pp. 63-75, 1989.

FRATESCHI, Y. A fisica da política: Hobbes contra Aristóteles. Campinas: Editora da Unicamp, 2008.

GREENLEAF, W. H. Hobbes: o problema da interpretação. In: QUIRINO, C. G.; SOUZA, M. T. S. (org.). O pensamento político clássico. São Paulo: T. A. Queiroz, 1980.

HOBBES, T. De corpore. In: The English works of Thomas Hobbes of Malmensbury. Now first collected and edited by Sir Willian Molesworth. London (1839-1845). Reprint Aelen: Scientia, 1966.

Leviathan, or the matter, forme and power of a Commonwealth ecclesiasticall and civil. Ed. C. B. Macpherson. Harmondsworth: Penguin Books, 1968.

Do cidadão. Elementos filosóficos a respeito do cidadão. Tradução de Renato Janine Ribeiro. São Paulo: Martins Fontes, 2002a.

. Elementos da lei natural e política. Tradução de Fernando Dias Andrade. São Paulo: Ícone, 2002b.

KAVKA, G. S. Hobbes's war of all against all. Ethics, v. 93, n. 2, p. 291-310, 1983.

KIDDER, J. Hobbes's “just man”. Reason Papers, n. 8, p. 1-15, Summer 1982.

LEIVAS, C. A paixão política do medo na concepção de Hobbes. Dissertatio, v. 33, p. 341353, Inverno 2011.

PACCHI, A. Hobbes and the passions. Topoi, v. 6, n. 2, p. 111-9, 1987.

POGREBINSCHI, T. O problema da obediência em Thomas Hobbes. Bauru: EDUSC, 2003.

SKINNER, Q. Razão e retórica na filosofia de Hobbes. São Paulo: UNESP, 1999. 
SORELL, T. Hobbes's scheme of the sciences. In: SORELL, Tom (ed.). The Cambridge Companion to Hobbes. Cambridge: University Press, 1996. p. 45-61.

SPRAGENS, T. A. The politics of motion: the world of Thomas Hobbes. Lexington: University Press of Kentucky, 1973.

STAUFFER, D. Strauss's discussion of Hobbes in "What is political philosophy?". Perspectives on Political Science, v. 39, n. 2, p. 87-91, 2010.

STRAUSS, L. $A$ filosofia política de Hobbes: suas bases e sua gênese. São Paulo: É realizações, 2016.

TOTO, F. Individuo, potere e relazione in Thomas Hobbes. La Società Degli Individui, v. 19, n. 55, p. 143-158, 2016. 